\title{
The Relationship between Serum Lipids and Breast Cancer in Libya
}

\author{
J. R. Peela ${ }^{1 *}$, A. M. Jarari ${ }^{2}$, Saeid Omer Alsoaeiti ${ }^{3}$, S. El Busaifi' ${ }^{2}$ H. El Awamy ${ }^{2}$ and Shakila Srikumar ${ }^{1}$ \\ ${ }^{1}$ Department of Biochemistry, Faculty of Medicine, Quest International University, Perak, Ipoh, Malaysia \\ ${ }^{2}$ Department of Biochemistry, Faculty of Medicine, Benghazi University, Benghazi, Libya \\ ${ }^{3}$ Department of Surgery, 7th October Hospital, Faculty of Medicine, Benghazi University, Benghazi, Libya
}

\begin{abstract}
Background: Carcinoma breast is one of the major surgical problems in Libya, particularly in younger female subjects. Since it is a commonly encountered health risk, it is important to know the etiology and associated related factors of breast cancer in Libya. There are conflicting reports regarding the association between the dietary lipids and serum lipid profiles and breast cancer. It is a fact that local dietary habits, environmental factors along with genetic predisposition play a role in the evolution of breast cancer. The present study was undertaken to identify whether there is such an association between alterations in lipid profile in carcinoma breast in a local Libyan subjects.
\end{abstract}

Material and methods: A total of 40 patients with various stages of breast cancer who were being treated at the department of surgery, 7th October hospital, Benghazi, Libya during 2009 and 2010 were recruited in the present study. Twenty one healthy volunteers were included as controls. These patients were categorized according to age, pre or post menopausal status and body mass index with their respective controls. Serum lipid profile was performed in all the cases and control groups using fasting blood samples. Total cholesterol, HDL-cholesterol and Triglycerides were measured by standard kit methods and LDL cholesterol was calculated using Fried Wald's formula.

Results: Serum total cholesterol and HDL cholesterol have been observed to be significantly elevated in patients with carcinoma breast when compared with those of controls ( $p=0.0046$ and 0.004 respectively). However, the serum levels of LDL cholesterol and triglycerides did not show any significant alteration between that of the cases studied and the controls ( $p=0.42$ and 0.092 respectively). In the case of premenopausal women, there is a significant rise of total cholesterol $(p=0.0186)$ and HDL cholesterol $(p=0.0031)$ whereas serum triglycerides $(p=0.335)$ and LDL cholesterol $(p=0.2617)$ had not shown any statistically significant variation. Furthermore, in the postmenopausal group, there is a significant elevation of serum triglycerides $(p=0.0094)$, total cholesterol $(p=0.0238)$ and HDL cholesterol $(p=0.0457)$ but LDL cholesterol had not shown any significant variation. There is a significant variation between the triglyceride levels of postmenopausal women and the premenopausal women $(p=0.0298)$.

Conclusion: This preliminary study has shown a significant alteration in serum lipid profile of breast cancer patients in the local Libyan female population. The interesting observation of high levels of HDL cholesterol in the patients' needs further evaluation by extending the investigation further on and also extending the study on larger study group. Postmenopausal women have shown an increase in serum triglycerides levels, with an increase observed in serum total cholesterol and HDL cholesterol levels when compared to that of premenopausal women.

Keywords: Breast cancer; Total cholesterol; Triglycerides; HDLcholesterol; LDL-cholesterol; Pre- and post-menopausal

\section{Introduction}

An increase in the incidence of cancers has been reported in the Arab countries [1]. This could be explained by the attribution of various factors such as the robust epidemiological control of infectious diseases, increase in the average life span of the general population, higher socio-economic status, smoking, higher incidence of hepatitis $\mathrm{B}$ and $\mathrm{C}$, and food fads socio-economic status. Breast cancer is one of the leading cancers, causing higher rate of morbidity and mortality comparable to that of other developed countries, however, with an earlier age of onset [2].

According to the Benghazi Cancer Registry, the incidence of cancer in women is 95 per 100,000 , out of which breast cancer was found to be $26 \%$ of the total cases of cancers [3]. Almost a decade ago, Singh and Al-Sudani [4] demonstrated that breast cancer is one of the top ten cancers responsible for higher mortality in Libya. In another study conducted between 1981 and 1985 [5], breast cancer was the most frequent tumor (29.8\%) in females and the majority of these patients were of a younger age group ( $72.3 \%$ below 50 years). Almost all the patients selected for our study were multiparous and were exposed to breast-feeding [6]. A recent literature review by Najjar and Easson [6] provided evidence that the average age of onset of breast cancer in Arab women is 48 years and is almost a decade sooner than their western counterparts and this warrants effective screening and management strategies [7].

The role of lipids in cancer in the maintenance of cell integrity is well documented [8]. Any alteration in the plasma lipid profile in breast cancer cases can increase its risk status and its measurement may be helpful in evaluation of prognostic and diagnostic importance of the disease [9]. Lipid peroxidation is one of the most important factors which involves cell membrane integrity and causation of cancer [10] However, published results have been inconsistent, and there is no data available among Libyan population on the relationship of serum lipid levels with cases of breast cancer. Therefore, this preliminary study was started with an objective of studying this relation and to extend

*Corresponding author: J. R. Peela, Department of Biochemistry, Faculty of Medicine, Quest International University, Perak, Ipoh, Malaysia, E-mail: pjagannadharao@hotmail.com

Received September 07, 2012; Accepted September 24, 2012; Published September 27, 2012

Citation: Peela JR, Jarari AM, El Saiety SO, El Busaifi S, Shakila S, et al. (2012) The Relationship between Serum Lipids and Breast Cancer in Libya. Biochem Anal Biochem 1:117. doi:10.4172/2161-1009.1000117

Copyright: (C 2012 Peela JR, et al. This is an open-access article distributed under the terms of the Creative Commons Attribution License, which permits unrestricted use, distribution, and reproduction in any medium, provided the original author and source are credited. 
this study further on to molecular level by continuing with a search on genetic markers on larger cohort in Libya.

\section{Material and Methods}

A total of 40 patients in various stages of breast cancer have been selected for the present study from department of surgery, 7th October hospital, Benghazi, Libya during 2009 and 2010. Their age varied from 20 to 65 years with mean age of 37 years and there were 21 healthy controls with age group of 20 to 55 years with mean age of 35 years. Out of 40 cases of breast carcinoma, 25 cases are of premenopausal women of age lesser than 47 and 15 cases are of post-menopausal women with an age group of 47 and above. The mean and standard deviation of general characters that is age, height, body weight and body mass index (BMI) are summarized in Table 1 . Serum Lipid profile was performed in all these patients and controls after an overnight fast. Total cholesterol (TC) was estimated using the Cholesterol Oxidase Phenol 4-Aminoantipyrine Peroxidase (CHOD-PAP) Method $[11,12]$. The GPO-PAP method was used to estimate triglyceride (TG) levels $[11,13,14]$. High density lipoprotein (HDL-C) cholesterol and low density lipoprotein (LDL-C) cholesterol was calculated using Friedewald's formula [15].

\section{Results}

Serum TC and HDL-C were significantly elevated in patients with carcinoma breast when compared with controls $(p=0.0046$ and 0.004 respectively). Whereas the levels of LDL-C and TGs did not show any significant changes between the cases studied and the controls $(p=0.42$ and 0.092 respectively). In the premenopausal women, there was a significant rise of TC $(\mathrm{p}=0.0186)$ and HDL-C $(\mathrm{p}=0.0031)$ whereas TGs $(p=0.335)$ and LDL-C $(p=0.2617)$ did not show a significant change against controls of their group. In the postmenopausal group, there is significant elevation of serum TGs $(p=0.0094)$, TC $(p=0.0238)$ and HDL-C $(\mathrm{p}=0.0457)$ but LDL-C did not show any significant difference against their control group. There is a significant difference in TG levels between postmenopausal woman and premenopausal woman $(\mathrm{p}=0.0298)$. More than $80 \%$ of all the patients are obese after calculating their BMI especially postmenopausal.

The results are summarized in Table 2.

\section{Discussion}

This study confirms the occurrence of dyslipidemia among women

\begin{tabular}{|c|c|c|c|c|}
\hline & Age & Weight & Height & BMI \\
\hline Controls & $35 \pm 7.5$ & $71 \pm 9.00$ & $164 \pm 6.1$ & $25.39 \pm 9.09$ \\
\hline Cases & $37.1 \pm 13.09$ & $71.36 \pm 13.30$ & $160.56 \pm 5.89$ & $31.494 \pm 5.53$ \\
\hline Premenopausal & $29.35 \pm 7.32$ & $67.8 \pm 13.85$ & $159.7 \pm 6.59$ & $31.606 \pm 4.68$ \\
\hline Postmenopausal & $52.6 \pm 6.22$ & $78.5 \pm 8.95$ & $162.3 \pm 3.91$ & $31.30 \pm 7.24$ \\
\hline
\end{tabular}

Table 1: The mean and standard deviation of general characters that is age height, body weight and body mass index (BMI).

\begin{tabular}{|c|c|c|c|c|}
\hline & $\mathrm{TC}(\mathrm{mg} / \mathrm{dL})$ & TG & HDL-C & LDL-C \\
\hline & \multicolumn{4}{|c|}{ Mean \pm STD $(p$ value $)$} \\
\hline Controls & $\begin{array}{c}152.38 \pm \\
35.39\end{array}$ & $99.28 \pm 31.10$ & $33.33 \pm 9.99$ & $98.33 \pm 33.92$ \\
\hline Overall & $\begin{array}{c}179.53 \pm 29.7 \\
(0.0046)\end{array}$ & $\begin{array}{c}142.73 \pm \\
112.81(0.092)\end{array}$ & $\begin{array}{c}44.1 \pm 14.02 \\
(0.004)\end{array}$ & $\begin{array}{c}105.79 \pm \\
31.09(0.42)\end{array}$ \\
\hline $\begin{array}{l}\text { Premenopausal } \\
\text { Women }\end{array}$ & $\begin{array}{c}177.5 \pm 29.65 \\
(0.0186)\end{array}$ & $\begin{array}{c}111.6 \pm 49.17 \\
(0.335)\end{array}$ & $\begin{array}{c}44.3 \pm 12.19 \\
(0.0031)\end{array}$ & $\begin{array}{c}109.62 \pm \\
29.23(0.2617)\end{array}$ \\
\hline $\begin{array}{l}\text { Postmenopausal } \\
\text { Women }\end{array}$ & $\begin{array}{c}183.6 \pm 30.96 \\
(0.0238)\end{array}$ & $\begin{array}{c}205 \pm 171.58 \\
(0.0094)\end{array}$ & $\begin{array}{c}43.7 \pm 17.86 \\
(0.0457)\end{array}$ & $\begin{array}{c}98.14 \pm 34.85 \\
(0.9884)\end{array}$ \\
\hline
\end{tabular}

Table 2: Lipid profile of Women with Breast Cancer. with among women with breast cancer. There is a significant rise in the TC and HDL-C levels in patients with breast cancer spread a wider range across all age groups ( $\mathrm{p}=0.0046$ and 0.004 respectively). Furthermore, TG levels rise significantly in postmenopausal women, compared to premenopausal women $(\mathrm{p}=0.0298)$ and controls $(\mathrm{p}=0.0094)$. Obesity is a growing health problem in the developed countries and increasingly, around the world. Excess body weight has been linked to an increased risk of postmenopausal breast cancer, and growing evidence also suggests that obesity is associated with poor prognosis in women diagnosed with early-stage breast cancer [16].

The current available data has shown conflicting evidence of the association of serum levels of various lipid components and breast cancer.

In a nested case-control study of breast cancer patients, HDL-C levels were not significantly different between the cases and controls. However, a statistically significant interaction between the HDL-C level and menopausal status at diagnosis was detected [17]. Ferraroni et al. [18] suggested that protective factors for breast cancer are associated with a lower level of HDL-C and vice versa, and high HDL-C levels should be especially checked in women aged 60 years, or in premenopausal women presenting a low BMI, or in postmenopausal women with an early menopause [18]. In a large Danish study, the relative risk was 0.3 ( $95 \% \mathrm{CI}=0.1-0.8)$ for women in the highest quartile of serum HDL cholesterol compared with women in the lowest quartile and the relation displayed a significant negative trend $(\mathrm{P}=0.01)$ [19]. Borrelli et al. suggesedt that a high serum HDL-C could be a biochemical index of increased risk of having breast cancer [20]. Studies by Qadir et al. [9], Shah et al. [21], Michalaki et al. [22], Kökoğlu et al. [23] and Bani et al. [24] have also shown an increase in HDL-C to be associated with an increased risk of breast cancer. In contrast to these findings, other studies suggest that low HDL cholesterol may be a marker of increased breast cancer risk among premenopausal [25] and postmenopausal women [26]. However, no statistically significant difference was observed in the HDL-C levels between the patients and controls [27].

TG levels were significantly higher in women with node-negative invasive cancer $(0.94+/-1.04 \mathrm{mg} / \mathrm{ml})$ than in those with no epithelial proliferation $(0.83+/-1.04 \mathrm{mg} / \mathrm{ml}, \mathrm{p}=0.03)$. This association persisted after adjustment for age, body size, lipids, reproductive and familial risk factors, and previous benign breast problems $(\mathrm{p}<0.01)$, in keeping with an independent association of elevated TG with breast cancer risk [28]. Several studies have also shown significant increase in TG levels of breast cancer patients [21-24,27]. However, other studies did not demonstrate a statistically significant increase in TG levels. In the Danish study, the higher serum TG was a part of the suggestion of a positive association with breast cancer incidence, but the trend was not significant $(\mathrm{P}=0.06)$ [19]. Vatten and Foss [29] demonstrated negative, but not statistically significant association for TG with breast cancer incidence, which showed further insignificance after adjustment for BMI and serum TC [29]. Similarly, Borrelli et al. did not find a significant correlation between serum TG levels and breast cancer [20].

Ray et al. [27] suggested that an increased serum TC level may play significant role in carcinogenesis. In a study by Qadir and Malik [8], a moderate increase in the plasma levels of cholesterol (21\%) was found in breast cancer patients when compared with normal subjects [9]. Bani et al. [24] found a higher level of serum TC in breast cancer patients prior to surgery [24].

On the contrary, plasma TC was significantly lower in patients with 
Citation: Peela JR, Jarari AM, El Saiety SO, El Busaifi S, Shakila S, et al. (2012) The Relationship between Serum Lipids and Breast Cancer in Libya. Biochem Anal Biochem 1:117. doi:10.4172/2161-1009.1000117

breast cancer in the studies by Shah et al. [21] and Kökoğlu et al. [23], Agurs-Collins et al. [27], Borrelli et al. [20] and Høyer and Engholm [19] did not find any significant association in the serum TC levels between breast cancer patients and controls.

Similar to other lipid components, there is contrasting evidence on serum LDL-C levels in breast cancer. Ray and Husain [30] suggested that the LDL-C levels are elevated, while Shah et al. [21] and Kökoğlu et al. [23] found a significant decrease in the LDL-C. Furthermore, AgursCollins et al. did not find a statistically significant difference between the LDL-C levels of breast cancer patients and controls [27].

\section{Conclusion}

The current study has shown a significant alteration in the serum lipid profile in breast cancer patients in the local female Libyan population. Postmenopausal women have shown an increase in serum triglycerides levels, with an increase observed in serum total cholesterol and HDL cholesterol levels when compared to that of premenopausal women. Majority of these patients in this study are obese, especially post menopausal women. It is highly recommended that people should reduce weight and control blood cholesterol levels in order to reduce risk of breast cancer. However, the major limitation of our study was the small sample size. Additionally, since there is contrasting evidence on the correlation of lipid levels and breast cancer, there is a need for large, multicentric and randomized trials.

\section{Acknowledgement:}

Our sincere thanks to NASR, Libya for funding this research project entitled "Evaluation of Diagnostic \& Prognostic markers of Carcinoma of Breas and Genetic variations amongst Libyans". Thanks to the staff of department of Biochemistry, Faculty of Medicine, Benghazi University for continued support and staff of department of surgery, 7th October hospital, Benghazi for providing samples and clinical data.

\section{References}

1. Anim JT (1990) Breast cancer in Arab women: A review. Emirates Med J 8 189-195.

2. Elattar I (2005) Cancer in the Arab World: Magnitude of the Problem. UICC March 21-25.

3. El Mistiri M, Verdecchia A, Rashid I, El Sahli N, El Mangush M, et al. (2007) Cancer incidence in eastern Libya: the first report from the Benghazi Cancer Registry, 2003. Int J Cancer 120: 392-397.

4. Singh R, Al-Sudani OE (2001) Cancer mortality in Benghazi, Libyan Arab Jamahiriya, 1991-96. East Mediterr Health J 7: 255-273.

5. Akhtar SS, Abu Bakr MA, Dawi SA, Huq IU (1993) Cancer in Libya--a retrospective study (1981-1985). Afr J Med Med Sci 22: 17-24.

6. Najjar H, Easson A (2010) Age at diagnosis of breast cancer in Arab nations. Int J Surg 8:448-452

7. Bielecka-Dąbrowa A, Hannam S, Rysz J, Banach M (2011) MalignancyAssociated Dyslipidemia. Open Cardiovasc Med J 5: 35-40.

8. Qadir MI, Malik SA (2008) Plasma lipid profile in gynecologic cancers. Eur J Gynaecol Oncol 29: 158-161.

9. Cejas P, Casado E, Belda-Iniesta C, De Castro J, Espinosa E, et al. (2004) Implications of oxidative stress and cell membrane lipid peroxidation in human cancer (Spain). Cancer Causes Control 15:707-719.

10. Kedzierska M, Olas B, Wachowicz B, Jeziorski A, Piekarski J (2010) The lipid peroxidation in breast cancer patients. Gen Physiol Biophys 29: 208-210.

11. Michael L, Bishop, Janet L, Duben-Engelkirk, Edward P, et al. Clinical Chemistry. Principles, Procedures, Correlations, $3^{\text {rd }}$ edition: $313-314,317,318$.

12. Allain CC, Poon LS, Chan CS, Richmond W, Fu PC (1974) Enzymatic determination of total serum cholesterol. Clin Chem 20: 470-475.
13. Werner M, Gabrielson DG, Eastman J (1981) Ultramicro determination of serum triglycerides by bioluminescent assay. Clin Chem 27: 268-271.

14. Fluitest LDL-CHOL Kit method: HDL-cholesterol precipitation for enzymatic assay for the direct quantitative determination of HDLcholesterol. Biocon Diagnostic Inc Hecke 8-34516 Vohl/Mariehagen Germany.

15. Friedewald WT, Levy RI, Fredrickson DS (1972) Estimation of the concentration of low-density lipoprotein cholesterol in plasma, without use of the preparative ultracentrifuge. Clin Chem 18: 499-502.

16. Ligibel J (2011) Obesity and breast cancer. Oncology (Williston Park) 25: 994-1000.

17. Moorman PG, Hulka BS, Hiatt RA, Krieger N, Newman B, et al. (1998) Association between high-density lipoprotein cholesterol and breast cancer varies by menopausal status. Cancer Epidemiol Biomarkers Prev 7: 483-488.

18. Ferraroni M, Gerber M, Decarli A, Richardson S, Marubini E, et al. (1993) HDL-Cholesterol and Breast Cancer: A Joint Study in Northern Italy and Southern France. Int J Epidemiol 22: 772-780.

19. Høyer AP, Engholm G (1992) Serum lipids and breast cancer risk: a cohort study of 5,207 Danish women. Cancer Causes Control 3: 403-408.

20. Borrelli R, del Sordo G, De Filippo E, Contaldo F, Parisi V, et al. (1993) High serum HDL-cholesterol in pre- and post-menopausal women with breast cancer in southern Italy. Adv Exp Med Biol 348:149-153.

21. Franky Dhaval Shah, Shilin Nandubhai Shukla, Pankaj Manubhai Shah, Patel HR, Prabhudas Shankerbhai Patel (2008) Significance of alterations in plasma lipid profile levels in breast cancer. Integr Cancer Ther 7: 33-41.

22. Michalaki V, Koutroulis G, Syrigos K, Piperi C, Kalofoutis A (2005) Evaluation of serum lipids and high-density lipoprotein subfractions (HDL2, HDL3) in postmenopausal patients with breast cancer. Mol Cell Biochem 268: 19-24.

23. Kökoğlu E, Karaarslan I, Karaarslan HM, Baloğlu H (1994) Alterations of serum lipids and lipoproteins in breast cancer. Cancer Lett 82: 175-178.

24. Bani IA, Williams CM, Boulter PS, Dickerson JW (1986) Plasma lipids and prolactin in patients with breast cancer. $\mathrm{Br} \mathrm{J}$ Cancer 54: 439-446.

25. Kucharska-Newton AM, Rosamond WD, Mink PJ, Alberg AJ, Shahar E, Folsom AR (2008) HDL-cholesterol and incidence of breast cancer in the ARIC cohort study. Ann Epidemiol 18: 671-677.

26. Furberg AS, Veierød MB, Wilsgaard T, Bernstein L, Thune I (2004) Serum high-density lipoprotein cholesterol, metabolic profile, and breast cancer risk. J Natl Cancer Inst 96: 1152-1160.

27. Agurs-Collins T, Kim KS, Dunston GM, Adams-Campbell LL (1998) Plasma lipid alterations in African-American women with breast cancer. J Cancer Res Clin Oncol 124: 186-190.

28. Goodwin PJ, Boyd NF, Hanna W, Hartwick W, Murray D, et al. (1997) Elevated levels of plasma triglycerides are associated with histologically defined premenopausal breast cancer risk. Nutr Cancer 27:284-292.

29. Vatten LJ, Foss OP (1990) Total serum cholesterol and triglycerides and risk of breast cancer: a prospective study of 24,329 Norwegian women. Cancer Res 50: 2341-2346.

30. Ray G, Husain SA (2001) Role of lipids, lipoproteins and vitamins in women with breast cancer. Clin Biochem 34:71-76. 